\title{
Determination of Tea Saponin in Camellia Seed Oil with UV and HPLC Analysis
}

\author{
Hadeil Omer Abdelgadir Ahmed, Chengming Wang* \\ Department of Food Science and Technology, Institute of Cereals, Oil and Vegetable Protein Engineering, \\ Huazhong Agricultural University, Wuhan, China \\ Email: ${ }^{*} 18971081261 @ 126 . c o m$
}

Received 6 December 2015; accepted 10 December 2015; published 17 December 2015

\begin{abstract}
A simple procedure is described for the HPLC and UV determination of tea saponin in tea seed oil. Determinate was accomplished with $U V$ wavelength detection $550 \mathrm{~nm}$ for saponification sample, and HPLC was done under conditions: C18 analytical column of TC-C18, 4. $6 \times 250 \mathrm{~mm}$, column temperature at room temperature, injected sample volume was $10 \mu \mathrm{L}$, mobile phase's methanol, flow-rate $0.8 \mathrm{ml} / \mathrm{min}$ and detection wavelength $280 \mathrm{~nm}$.
\end{abstract}

\section{Keywords}

Tea Seed Oil, Saponification, UV, High Performance Liquid Chromatography (HPLC)

\section{Introduction}

Tea seed oil from Camellia is edible oil with a characteristic of sweet fragrance. Cold pressed from Camellia oleifera and Camellia sinensis has an extensive use in China as cooking oil [1]. It is mainly produced in Hunan and Jiangxi provinces of China. It has been used in herbal medicine because it is considered as a high nutritionary dietary supplement that benefits the digestive system, reduces bad cholesterol, lowers blood pressure, regulates the nervous system and strengthens the immune system. Tea seed oil is recommended by the Food and Agriculture Organization of the United Nation (FAO) as a high quality, healthy vegetable oil because of its nutritional value, which is comparable to olive oil in terms of high oleic acid content, low saturated fat, high antioxidants, and excellent storage qualities. This oil should be considered to tea tree oil, which is entirely separate oil [2]-[4]. Saponin has many biologically active roles, such as hemolysis and fish toxicity. Tea saponin in seed shell of oil-tea camellia is about $5 \%-8 \%$, which increases substantially the secondary value of the oil-tea camellia [5] [6]. HPLC detectors were used to estimate tocopherols including ultraviolet, fluorescence and anisometric [7]-[9]. Reversed-phase HPLC currently is the most popular and reliable technique for the analysis of phenolic compounds. The technique has been used mainly with UV detection [10] [11]. Fluorescence detection is more sensitive and selective than UV detection but can't utilize fluorescence in samples-free alcohol [12]. A saponification step is thus required in order to convert oil esters to their uncontrolled alcohol. Reports on simultaneous analysis of phenolic substances and oil by HPLC [13] [14] dealt with synthetic phenolic antioxidants either in standard mixtures or directly in oil samples with no prior extraction or clean up. With direct injection, most compounds of lower concentrations and extinction coefficients cannot be detected. No reference was found "Corresponding author. 
in the literature on the simultaneous determination of natural phenolic compounds after their co-extraction from vegetable oils. The aim of this study was to improve a simple method for the determination of tea saponin in tea seed oil by HPLC and UV detection.

\section{Material and Methods}

\subsection{Main Materials and Instruments}

The main materials and instrument used in this study: tea seed oil, tea saponin, distilled water, concentrated sulfuric acid, 77\% sulfuric acid, 8\% vanillin, sodium hydroxide $(\mathrm{NaOH})$, ethanol and methanol; UV-2008 (UVvisible spectrophotometer scanning) and HPLC as equipment instruments. The materials and the instruments used in this experiment were from the laboratory of the Academy of Cereals, Oil and Vegetable Protein Engineering, College of Food Science and Technology in Huazhong Agricultural University, Wuhan, China.

\subsection{UV-Analysis}

\section{Preparation of Samples}

1) Saponification solution

$6 \mathrm{ml}$ of tea oil was weighed in $100 \mathrm{ml}$ flask; $30 \mathrm{ml} 1 \mathrm{~mol} / \mathrm{L} \mathrm{NaOH}$ solution was added and heated for $1 \mathrm{~h}$ at $95^{\circ} \mathrm{C}$. Remove the ethanol by used decompression of distilled at normal temperature, collect the solution and completed the volume to $100 \mathrm{ml}$ distilled water [15].

2) Standard curve for tea saponin:

a) Preparation of standard tea saponin solution and method of measurement

The standard tea saponin solution $(0.95 \mathrm{mg} / \mathrm{ml})$ was prepared in the following steps: $0.1 \mathrm{~g}$ standard tea saponin powder (containing 95\% tea saponin) was weighted precisely put into a $100 \mathrm{ml}$ volumetric flask. The saponin powder was dissolved in 50\% ethanol solution, and then additional ethanol was added to volume, spinal solution $0.95 \mathrm{mg} / \mathrm{ml}$. The standard solution $(0.5 \mathrm{ml})$ was measured and into $10 \mathrm{ml}$ test tubes with a stopper, then put in an ice-water bath, and then $0.5 \mathrm{ml}$ of $8 \%$ vanillin solution and $5 \mathrm{ml}$ of $77 \%$ sulfuric acid was added. After shaking, the test tube was transferred to an intermittent warm water bath (60C) for $20 \mathrm{~min}$, then for color development cooled in an ice-water bath for $10 \mathrm{~min}$. The sample was allowed to reach room temperature before detecting the absorbance of the solution was used $1 \mathrm{~cm}$ cuvette at the wavelength of maximum absorption $550 \mathrm{~nm}$ in the UV-visible (V-2008 UV-visible spectrophotometer scanning). The blank solution 1:8 (volume ratio) mixtures of vanillin solution and sulfuric acid were prepared as above [16].

3) Standard curve determination:

Series of the standard solution $(0 \mathrm{ml}, 0.1 \mathrm{ml}, 0.2 \mathrm{ml}, 0.3 \mathrm{ml}, 0.4 \mathrm{ml}$ and $0.5 \mathrm{ml})$ were taken and the mixed solutions were prepared by the method described as above for measuring absorbance values. The resulting standard curve was assessed with Microsoft excel [5].

\subsection{HPLC-Analysis}

Preparation and Measurement Method of a Standard Solution

Standard tea saponin $(0.4350 \mathrm{~g})$ was dissolved in $80 \%$ ethanol in a $50 \mathrm{ml}$ volumetric flask. For a final concentration of $8.7 \mathrm{~g} / \mathrm{L}$. Different weights $(0.02,0.1,0.2,0.8,1 \mathrm{~g})$ was taken placed in $50 \mathrm{ml}$ volumetric flasks, ethanol (80\%) was added to the line, shaken, filtered through a $0.45 \mu \mathrm{m}$ micro porous membrane filter, then placed in cooled storage [17]. Conditions of HPLC equipment are as below: C18 analytical column of TC-C18, $4.6 \times 250$ $\mathrm{mm}$; column temperature at room temperature; injected sample volume $10 \mu \mathrm{L}$; mobile phases $10 \%-100 \%$ methanol; flow-rate $0.8 \mathrm{ml} / \mathrm{min}$; detection wavelength $280 \mathrm{~nm}$ [18].

1) Sample preparation

Saponification solution ( $1 \mathrm{~g}$ ) was evaluated and diluted to the mark in $50 \mathrm{ml}$ volumetric flasks with $80 \%$ ethanol under sanction 5 min, then filtered using micro membrane and stored under refrigerator at $6^{\circ} \mathrm{C}-8^{\circ} \mathrm{C}$, before analysis by HPLC [17].

\section{Results and Discussion}

\subsection{Determination of the Formula}

According to the absorbance of the standard tea saponin solution and the standard curve (see Figure 1 \& Table 1) 


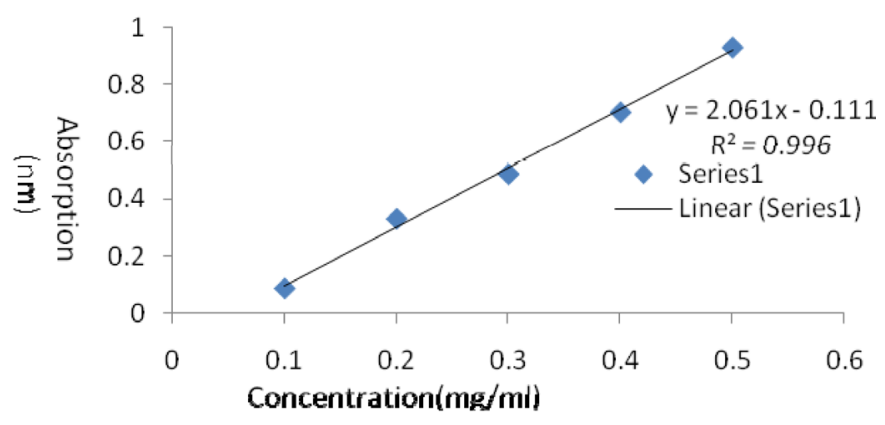

Figure 1. Standard curve.

Table 1. Standard curve (UV).

\begin{tabular}{cc}
\hline Concentration $(\mathrm{mg} / \mathrm{ml})$ & Absorption \\
\hline 0.1 & 0.086 \\
0.2 & 0.33 \\
0.3 & 0.486 \\
0.4 & 0.703 \\
0.5 & 0.93 \\
Sample & 0.740 \\
\hline
\end{tabular}

with vanillin sulfuric acid colorimetric method [20], which is obtained at the maximum absorption wavelength of $550 \mathrm{~nm}$ at different concentration of tea saponin, the regression equation is as follows:

$$
Y=2.061 x-0.111
$$

Then combined with the standard curve, tea saponin content is calculated with equation:

$$
\text { Teasaponin }(\%)=\frac{(A+0.111)}{2.061 V} * N / W
$$

where:

A: absorbance of oil sample, $V$ : volume of tube solution, $N$ : dilution, $W$ : weight of sample (mg)

\subsection{Single Factor Experiment}

Figure 2 \& Table 2 explained the chromognic single factor (vanillin and sulfuric acid) in difference volumes $3.5-5.5 \mathrm{ml}$, but the best results at $5 \mathrm{ml}$ for each one.

\subsection{Influence of Color Temperature}

Figure 3 \& Table 3 shown the absorption of tea saponin increased when the temperature rises from $40^{\circ} \mathrm{C}$ to 80 ${ }^{\circ} \mathrm{C}$. However, the good absorption began to decline when the temperature higher than $40^{\circ} \mathrm{C}$. Optimum color temperature is $40^{\circ} \mathrm{C}-60^{\circ} \mathrm{C}$.

\subsection{Influence of Time}

In order to find out the optimum time, several different time tests were conducted. The results (Figure 4 \& Table 4) showed that the tea saponin absorption rate increased over time, suggesting balance point of the absorption could reach at that time, which could also be the optimum time is15 - 25 min.

\subsection{Optimization of Tea Saponin Conditions and Selection of the Optimum Level}

Orthogonal analysis (Table 5) showed that the main determinants order is A > B > C > D. The higher temperature showed greatest complete reaction of the tea saponin. From the results of orthogonal experiment, the best 


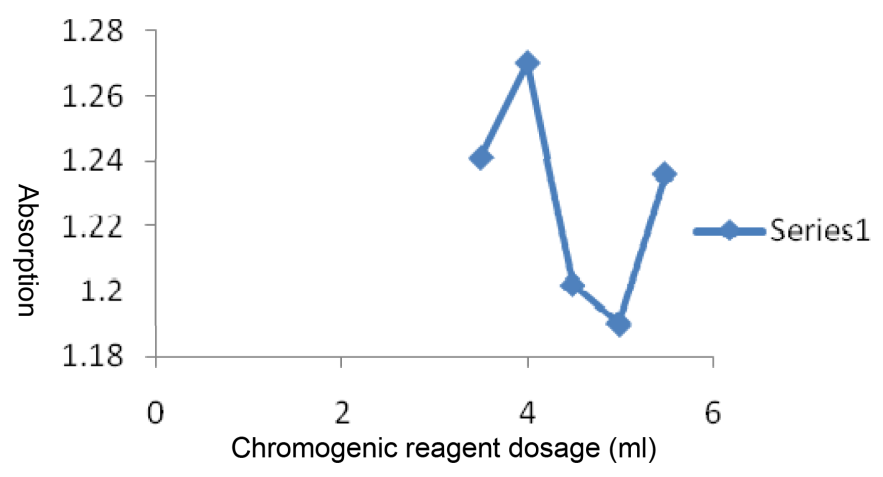

Figure 2. Chromogenic single factor experiment.

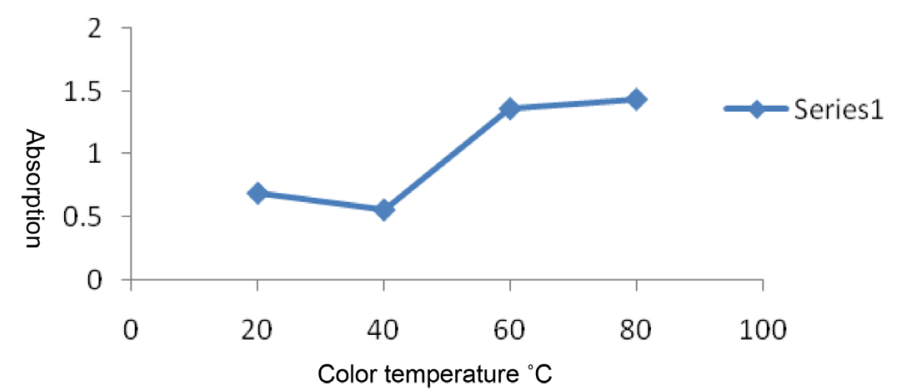

Figure 3. Color temperature single factor.

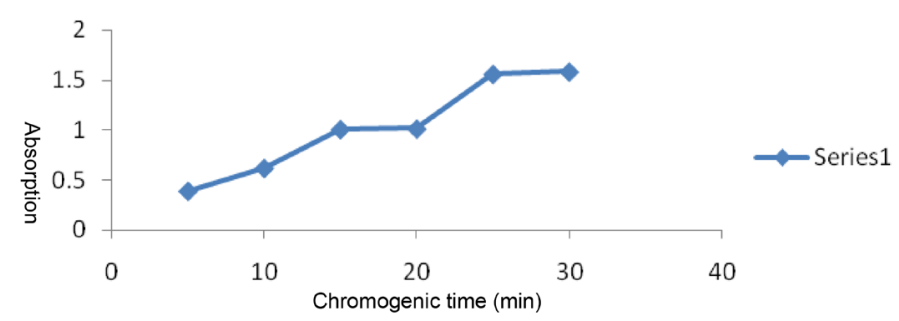

Figure 4. Chromogenic time single factor.

Table 2. Univariate analysis.

\begin{tabular}{cc}
\hline Chromognic reagents & Absorption \\
\hline 3.5 & 1.241 \\
4.0 & 1.270 \\
4.5 & 1.202 \\
5.0 & 1.190 \\
5.5 & 1.236 \\
\hline
\end{tabular}

Table 3. Influence of color temperature.

\begin{tabular}{cc}
\hline Color temperature ${ }^{\circ} \mathrm{C}$ & Absorption \\
\hline 20 & 0.694 \\
40 & 0.562 \\
60 & 1.358 \\
80 & 1.432 \\
\hline
\end{tabular}


Table 4. The color of time.

\begin{tabular}{cc}
\hline Chromogenic time (min) & Absorption \\
\hline 5 & 0.389 \\
10 & 0.618 \\
15 & 1.007 \\
20 & 1.013 \\
25 & 1.561 \\
30 & 1.585 \\
\hline
\end{tabular}

Table 5. An experimental program.

\begin{tabular}{|c|c|c|c|c|c|}
\hline No & Level & Reagent (ml) & Temperature $\left({ }^{\circ} \mathrm{C}\right)$ & Time (min) & Reagent ratio \\
\hline 1 & A1B1C1D1 & 3.5 & 40 & 15 & $0.25: 4.25$ \\
\hline 2 & A1B2C2D2 & 3.5 & 50 & 20 & $0.50: 4.00$ \\
\hline 3 & A1B3С-3D3 & 3.5 & 60 & 25 & $0.75: 3.75$ \\
\hline 4 & A2B1C2D3 & 4.0 & 40 & 20 & $0.75: 3.75$ \\
\hline 5 & A2B2C3D1 & 4.0 & 50 & 25 & $0.25: 4.25$ \\
\hline 6 & A2B3C1D2 & 4.0 & 60 & 15 & $0.50: 4.00$ \\
\hline 7 & A3B1C3D2 & 4.5 & 40 & 25 & $0.50: 4.00$ \\
\hline 8 & A3B2C1D3 & 4.5 & 50 & 15 & $0.75: 3.75$ \\
\hline
\end{tabular}

condition for tea saponin is A3B3C2D3, at temperature is $60^{\circ} \mathrm{C}$, ratio of chromogenic reagent $0.75: 3.75$, 4.5 , and time is 20 minutes.

\subsection{Formula Calculation}

Mobile phases (water, methanol) were checked at various compositions in an attempt to resolve with standard tea saponin and saponification sample by HPLC. Figure 5 \& Table 6 illustrates the universal curve of stock tea saponin by HPLC. Then combined with the standard curve, tea saponin content is calculated with equation:

$$
Y=42541 x-2354
$$

where:

$Y$ : an area of standard tea saponin, $x$ : different concentration $\mathrm{mg} / \mathrm{ml}$

\subsection{Standard Tea Saponin}

Figure 6 as showed the standard tea saponin, measured at a wavelength $280 \mathrm{~nm}$, a retention time was 45 min; it can be observed that: chromatography peak shape is high; few impurity peaks before the tall peak, higher peak at $21 \mathrm{~min}$.

\subsection{Saponification Oil Sample}

Figure 7 showed, separation and analysis time is brief, measured at $280 \mathrm{~nm}$ wavelengths and in retention time 45 minimums. They are few impurity peaks before the sample peak, the taller peak at 19.637 min; within the time of higher peak of tea saponin. No impurity peaks out after a sample peak. Standard peak time it's long (21 min), Compared with previous studies; time peaks at (4. $295 \mathrm{~min}, 14.8 \mathrm{~min}$ and $16.3 \mathrm{~min}$ ) [18] [19] in difference 


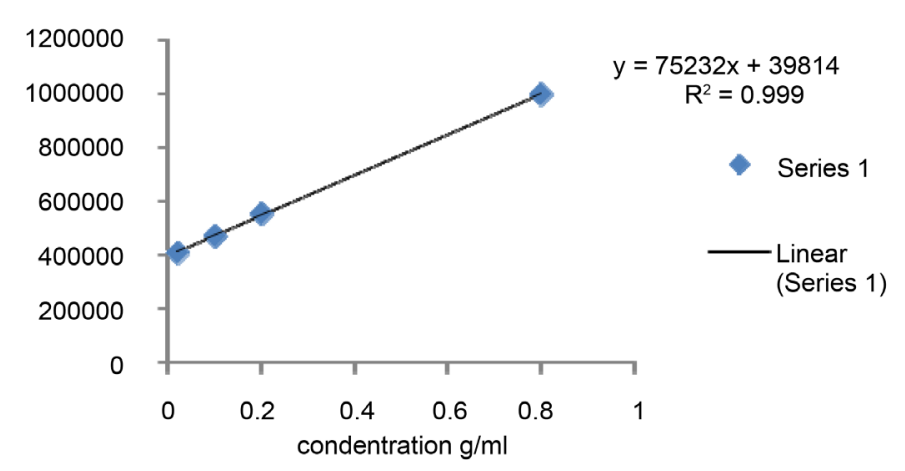

Figure 5. Standard curve of Standard tea saponin.

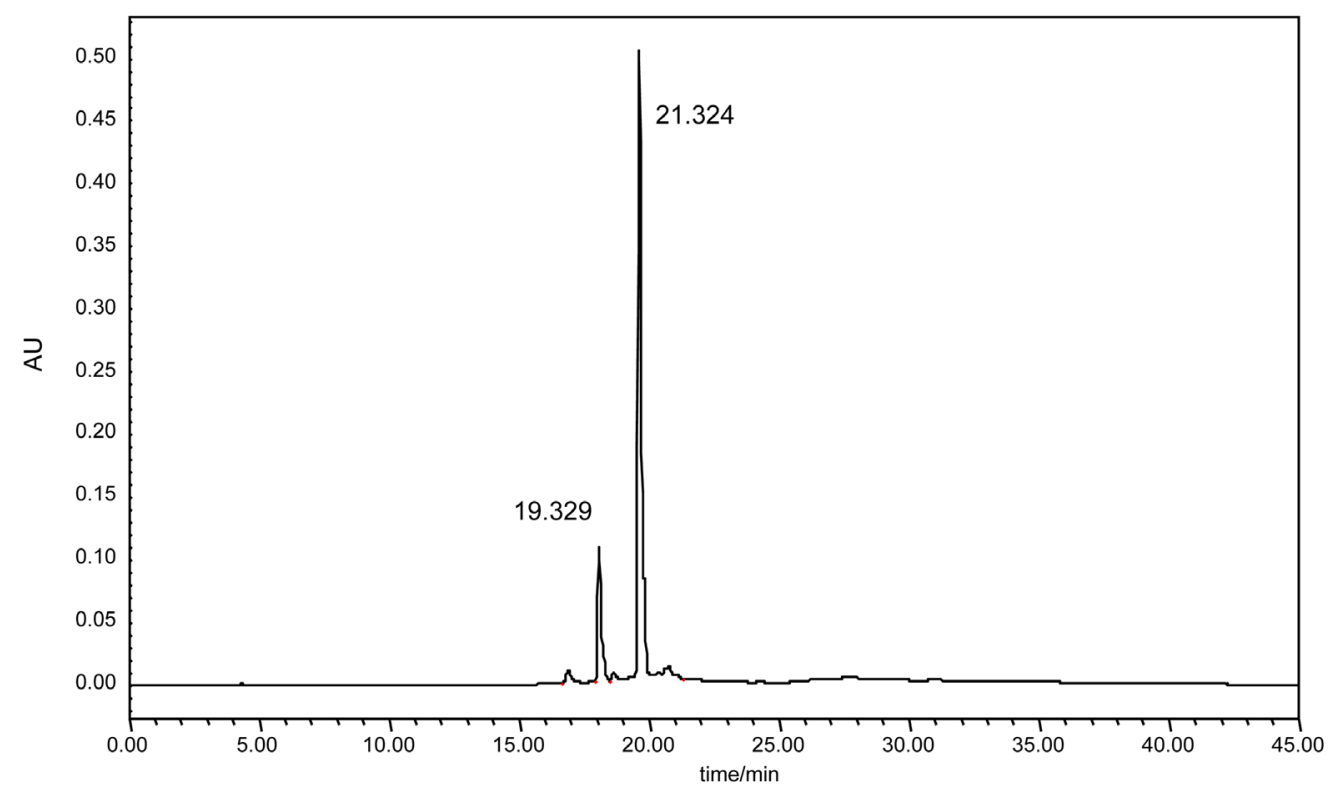

Figure 6. Chromatography of Standard tea saponin.

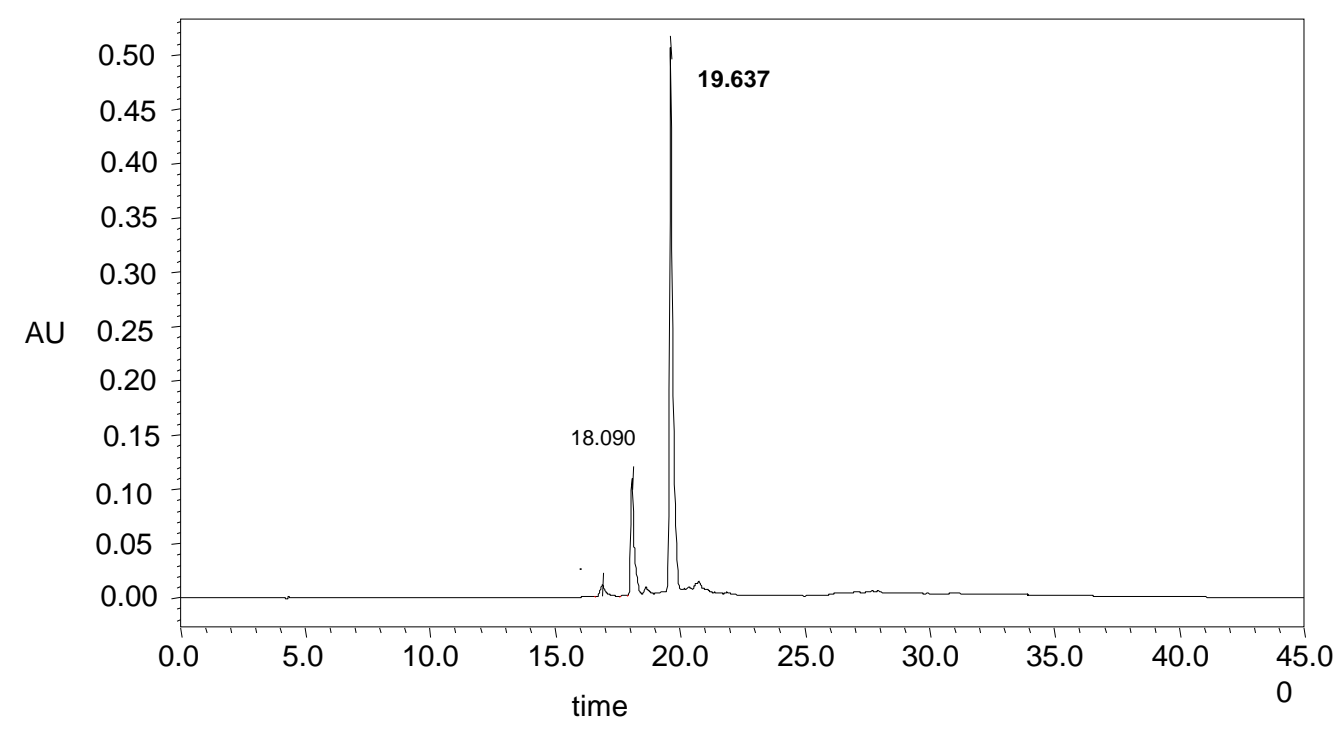

Figure 7. Chromatography of saponification oil sample. 
Table 6. Standard curve (HPLC).

\begin{tabular}{cc}
\hline Concentration $\mathrm{g} / \mathrm{ml}$ & Area \\
\hline 0.02 & 409,745 \\
0.1 & 471,741 \\
0.2 & 554,991 \\
0.8 & 998,698 \\
Sample $1 \mathrm{~g}$ & 105,772 \\
\hline
\end{tabular}

conditions. However, these compounds have a complex phenolic nature and correspond to a hydroxymethyl derivative [20].

\section{Conclusion}

We use the two based linear regression equations to calculate the oil tea saponin, and the tea saponin quality scores are $1.5 \%, 1.6 \%$; the results are basically the same. Tests to prove: Determination of tea saponin in camellia oil methods (UV and HPLC) is simple and the effect is great. Using methanol as a solvent with slow flow rate, the consumption has become less, and it's easy to operate, high recoveries and relative standard deviation are small, precise and accurate.

\section{References}

[1] Carpenter Jr., A.P. (1979) Determination of Tocopherols in Vegetable Oils. Journal of the American Oil Chemists Society, 5, 668-671. http://dx.doi.org/10.1007/BF02660070

[2] Kelvin, O.G., Thomas, K.W., Okong’o, K.M. and Francis, W. (2013) Extraction and Analysis of Tea (Camellia sinensis) Seed Oil from Different Clones in Kenya. African Journal of Biotechnology.

[3] Peter, J.L. and Di Gioia, J. (2009) Characterization of Tea Seed Oil for Quality Control and Authentication. Waters Journal.

[4] Ma, L., Zhong, H. and Chen, Y. (2012) Study on Tea Saponin Extraction from Shell of Oil-Tea Camellia Seeds. International Conference on Mechanical Engineering and Material Science.

[5] Yan, Y., Wu, Z.L., Zhao, Y.L. and Jiang, C.S. (2011) Separation of Tea Saponin by Two-Stage Foam Fractionation. Separation and Purification Technology.

[6] Jie, L.H., Shao, P., Dan, F.H., Chang, L. and Ming, Y.X. (2012) Extraction of Saponin from Camellia oleifera Cake and Evaluation of Its Antioxidant Activity. International Journal of Food Science and Technology.

[7] Dionisi, F., Prodolliet, J. and Tagliaferri, E. (1995) Assessment of Olive Oil Adulteration by Reversed-Phase HighPerformance Liquid Chromatography/Amperometric Determination of Tocopherols and Tocotrienols. Journal of the American Oil Chemists Society, 72, 1505-1511. http://dx.doi.org/10.1007/BF02577844

[8] IUPAC (1987) Standard Methods for The analysis of Oils, Fats and Derivatives. Method 2.411 (7th Edition). International Union of Pure and Applied Chemistry, Blackwell Scientific Publication, London.

[9] Montedoro, G., Servili, M., Baldioli, M. and Miniati, E. (1992) Simple and Hydrolyzable Phenolic Compounds in Virgin Olive Oil. 1. Their Extraction, Separation, and Quantitative and Semiquantitative Evaluation by HPLC. Journal of Agriculture and Food Chemistry, 40, 1571-1576. http://dx.doi.org/10.1021/jf00021a019

[10] Pirisi, F.M., Angioni, A., Cabras, P., Garau, V.L., Di Teulada, M.T.S., dos Santos, M.K. and Bandino, G. (1997) Phenolic Compounds in Virgin Olive Oils. 1. Low-Wavelength Quantitative Determination of Complex Phenols by HighPerformance Liquid Chromatography under Isocratic Elution. Journal of Chromatography A, 768, 207-213. http://dx.doi.org/10.1016/S0021-9673(96)01034-5

[11] Hoehler, D., Frohlich, A.A., Marquardt, R.R. and Stelsovsky, H. (1998) Extraction of Tocopherol from Serum Prior to Reversed-Phase Liquid Chromatography. Journal of Agriculture and Food Chemistry, 46, 973-978. http://dx.doi.org/10.1021/jf970596i

[12] Andrikopoulos, N.K., Brueschweller, H., Felber, H. and Taeschler, Ch. (1991) HPLC Analysis of Phenolic Antioxidants, Tocopherols and Triglycerides. Journal of the American Oil Chemists Society, 68, 359-364. http://dx.doi.org/10.1007/BF02663750

[13] Indyk, H. and Woollard, D.C. (1986) Antioxidant Analysis in Edible Oils and Fats by Normal-Phase High-Perfor- 
mance Liquid Chromatography. Journal of Chromatography, 356, 401-408. http://dx.doi.org/10.1016/S0021-9673(00)91506-1

[14] Gao, Z., Liu, X., Zhou, Y. and Wu, M. (2007) Study on Phytosterol Extraction from Crude Rapeseed Oil. Academic Periodical of Farm Products Processing.

[15] Felix, M.C. (2007) Chinese Herbal Drug Research Trends. P. 152.

[16] Li, X.Q., Ji, C., Sun, Y.Y., Yang, M.L. and Chu, X.G. (2008) Analysis of Synthetic Antioxidants and Preservatives in Edible Vegetable Oil by HPLC/TOF-MS Food Chemistry.

[17] Zhong, S., He, G.W., Zhang, C.J., Hua, H. and Yan, Q.Y. (2008) RP2HPLC Determination of Tea Saponin in Tea2 Seed Cake. China Academic Journal.

[18] Tasioula-Margari, M. and Okogeri O. (2001) Simultaneous Determination of Phenolic Compounds and Tocopherols in Virgin Olive Oil Using HPLC and UV Detection. Food Chemistry. http://dx.doi.org/10.1016/S0308-8146(01)00176-5

[19] Okogeri, O. and Tasioula-Margari, M. (2000) Evaluation of Greek Virgin Olive Oil Phenolic Compounds by HPLC/ UV and GC/MS. In: 2000 IFT Annual Meeting Book of Abstracts, Illinois: Institute of Food Technologists, Dallas, Texas, 113.

[20] Zhu, X. (2012) Transesterified Soybean Oil Technology and Establishment of Rapid Determination of Phytosterol. Master Thesis, Northeast Agricultural University. 